\title{
viewpoint
}

\section{A national effort}

\author{
Recent developments in Canadian biomedical and health research support
}

\author{
John J.M . Bergeron \& Sean C. Taylor
}

$\mathrm{T}$ he 1990s were a difficult time for biomedical research in Canada. The U SA vastly expanded its funding for biomedical research, particularly by doubling the budget of the US National Institutes of $\mathrm{H}$ ealth (N IH), and many countries, including Japan, China and several EU nations, heavily invested in genomics research. However, repeated budgetary setbacks during the economic recession of the 1990s led to the curtailment of large-scale research projects set up via the Canadian Genome Analysis and Technology Program. At the same time, federal funding through the Canadian Medical Research Council (MRC) only awarded small operating grants for research groups. Internationally recognized Canadian researchers, such as Charles Scriver of McGill University (Montreal, Quebec)who was instrumental in encouraging the Howard Hughes Medical Institute to prioritize the Human Genome Project (CookDeegan, 1994)- and Ronald W orton-CEO and Scientific Director of the $\mathrm{O}$ ttawa Health Research Institute (O ntario)-were concerned that Canada was at risk of being shut out of impending large-scale genomesequencing efforts. According to Scriver, without a dedicated programme in one form or another, Canada would no longer remain competitive and would become marginalized in all areas of the life sciences within a decade (Cook-D eegan, 1994).

Nevertheless, non-Canadian funding sources identified a cohort of Canadian excellence during this period. The Howard Hughes Medical Institute funded 12 Canadian scientists through its International Research Scholar Awards. The Human Frontier Science Program, based in Strasbourg, France, supported a small number of Canadian graduate students for postdoctoral training in US and European labs.
In addition, a small number of Canadian principal investigators working in Canadian laboratories received operating-fund grants from the $\mathrm{N} \mathrm{IH}$.

\section{According to Scriver, without a dedicated programme in one form or another, Canada would no longer remain competitive and would become marginalized in all areas of the life sciences within a decade}

Concerned about the increasing international competition for high-calibre scientists, particularly from the USA (Industry Canada, 1999), and eager to elevate the country's status as one of the international leaders in research, Canadian politicians realized that they had to significantly increase the capacity of universities to conduct excellent research and train researchers. This led to a number of activities and new funding opportunities with the aim of increasing Canada's capacity in the life sciences. In addition to investing more money into research and research infrastructure, these initiatives involved a major reorganization of funding agencies, which is now reaping benefits after only a few years. At the federal level, this involved the creation of several programmes and corporations, which we describe in more detail below, as well as increasing funding for the National Sciences and Engineering Research Council and the Social Sciences and Humanities Research Council (Canada Research Chairs Program, 2002). Each of these granting agencies is under the auspices of either the Health Canada or
Industry Canada ministries, but remains independent of the government (Fig 1). This recent flurry of initiatives has had a remarkable impact on the Canadian biomedical and health research arena.

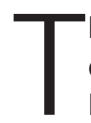

he federal government created the experimental $\mathrm{N}$ etworks of Centres of Excellence (NCE; www.nce.gc.ca) programme as early as 1990 . This new funding mechanism has two mandates: to improve communication through networking in order to overcome the great distances in Canada that tended to prevent direct collaborations, and to create partnerships among universities, industry, government and not-for-profit organizations in order to turn Canadian research and entrepreneurial talent into economic and social benefits for all citizens. O ne example of a high-profile NCE is the Protein Engineering Network of Centres of Excellence (PENCE), which in 2001 shifted its focus to proteomics. PEN CE has contributed $C \$ 1.395$ million to proteomics projects and hosts an annual Canadian conference on proteomics in an effort to connect and service the broader Canadian proteomics research community. It also provides a public database of researchers, companies and centres involved in proteomics.

The N CE has been a permanent funding source for biomedical research since 1997 and, measured in terms of personnel and biotech companies, it has been successful in fulfilling its tasks. For example, at least 19 spin-off companies are created each year and almost 6,000 highly qualified professionals-including researchers, research associates, postdoctoral fellows, graduate students, summer students and technicians-are trained. As of 2002-2003, 756 companies (that supplied more than 


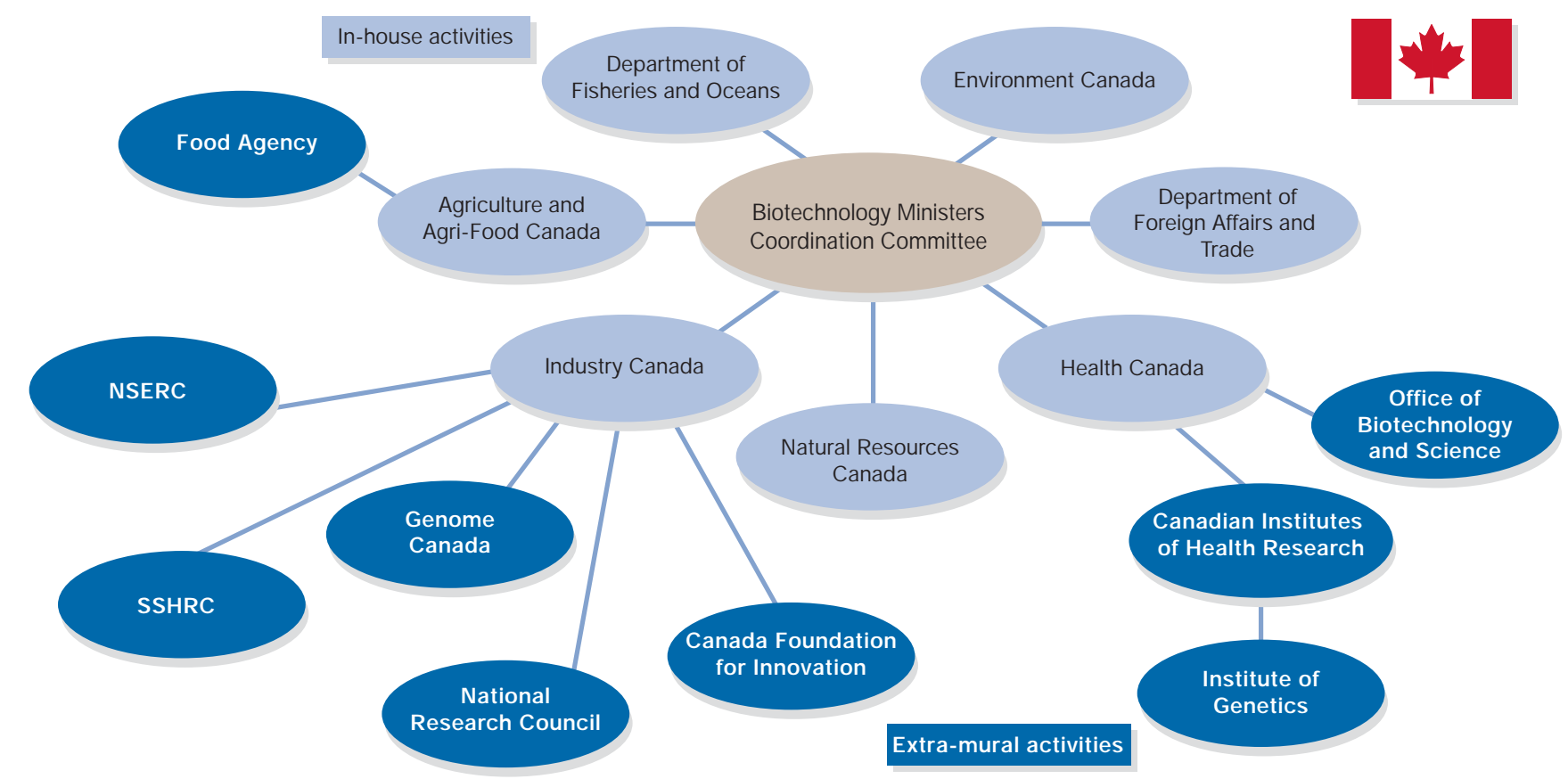

Fig1 | Governance of biotech activities in Canada. NSERC, National Sciences and Engineering Research Council; SSH RC, Social Sciences and Humanities Research Council.

C $\$ 33$ million of additional investments), 213 provincial and federal government departments and agencies, 48 hospitals, 153 universities and more than 280 other organizations from Canada and abroad have become involved in the NCE programme.

\section{Concerned about the increasing international competition for high-calibre scientists... Canadian politicians realized that they had to significantly increase the capacity of universities to conduct excellent research and train researchers}

As part of Canada's commitment to being one of the top five research nations in the world, the government also transformed the MRC into the Canadian Institutes of Health Research (CIHR; www.cihr-irsc.gc.ca) in 2000, while broadening its mandate and almost tripling its budget. The $\mathrm{CIHR}$ now funds all areas of research that pertain to health, including biomedical and clinical health services and population health research. In addition, 13 virtual institutes were created, including the Institutes of Genetics, Cancer Research and Aboriginal Peoples' Health. The CIHR's budget grew from C $\$ 265$ million in 1999 (the last year of the MRC's existence) to C $\$ 662$ million in 2004-2005. The average grant size increased from $C \$ 70,000$ in 1999 to $\mathrm{C} \$ 110,000$ today. Most grants in the biomedical field are between $C \$ 150,000$ and $C \$ 250,000$ per year for five years. The agency supports both individual operating grants as well as institute-driven multidisciplinary research; team grants are in the range of $C \$ 300,000-\$ 1,000,000$ per year. $O$ verall, the CIHR is one of Canada's leading health research agencies, funding more than 5,000 primary investigators, students and postdoctoral fellows.

A nother initiative that has had a major impact on biomedical research is the Canada Foundation for Innovation (CFI; www.innovation.ca). Created in 1997, the CFI began disbursing funds in 1999 from several separate funding sources (Fig 2). In total, the CFI has invested more than $C \$ 2.5$ billion directly over the past seven years and has entrusted a total of C $\$ 3.65$ billion (CFI, 2003). It is anticipated that the total capital investment by the CFI, the research institutions and their partners will exceed C $\$ 10$ billion by 2010 . Institutions report that the CFI has had a major impact on attracting researchers, postdoctoral fellows and graduate students.
On average, between $C \$ 200$ and $\$ 400$ million per year of CFI funds has been earmarked for the Innovation Fund, the largest project within the CFI. This fund focuses on infrastructure to support the large-scale research projects of academic institutions. The CFI provides $40 \%$ of the total funds requested; the remaining $60 \%$ usually comes from non-federal sources. Separate applications are usually made to the provinces for up to $40 \%$ of the budget; the final $20 \%$ usually comes from industry or other sources. The majority of grant applications to this fund fall in the range C \$2-\$20 million. The CFI has helped to build world-class research facilities across Canada with the most advanced equipment to perform science on a globally competitive scale. The Innovation Fund projects are also credited with helping to attract 1,718 new researchers and retain 1,425 others, more than 3,000 postdoctoral fellows $(55 \%$ from abroad), almost 9,000 postgraduate students (approximately $30 \%$ from abroad), and advancing the training of almost 6,200 undergraduate students (CFI, 2003).

Initially, the Innovation Fund did not include money to operate or maintain the infrastructure that was created. The CFI corrected this by adding up to $12 \%$ to each application's budget for 2002 and all 
subsequent fiscal years. This Infrastructure $O$ perating Fund supports a team of qualified personnel necessary to maintain the newly acquired infrastructure and equipment, but does not cover the costs of the people required to perform the research, develop new projects or manage the resources to drive projects forwards.

Whereas the CFI concentrates its budget on creating and maintaining research infrastructure, the goal of the Canada Research Chairs Program (www.chaires.gc.ca) is to support Canadian and foreign researchers working in Canada. Established in 2000, it allows Canadian universities to attract and retain outstanding national and international researchers at the peak of their careers, or whose careers are ready to accelerate. This C $\$ 900$ million programme, funded by the Government of Canada, is investing in research excellence by establishing 2,000 Canada Research Chairs in Canadian universities. There are two kinds of chair: Tier 1 Chairs are awarded to experienced researchers whose peers acknowledge them as world leaders in their field. These appointments are worth $C \$ 200,000$ a year for seven years and are renewable. Tier 2 Chairs support researchers whose peers acknowledge them as having the potential to become world leaders in their field. These appointments are worth $C \$ 100,000$ a year for five years, and can be renewed once. So far, 1,035 chairs have been awarded to researchers from across Canada and around the world. International researchers constitute $14 \%$ of chair holders and another $14 \%$ are expatriates.

The N ew O pportunities Fund, specifically targeted to newly recruited faculty members in their first full-time academic appointment

\section{This unification of funding sources and the creation of a more comprehensive infrastructure to support the biomedical research community has significantly improved Canada's research profile over the past four years}

in a Canadian institution, also assists universities in attracting and retaining high-calibre researchers, creating innovative research training environments and preparing Canadians for research and other careers that will benefit the country. Using these funds, Canadian research institutions have been able to offer their recruits competitive salary packages. The average minimum award is C $\$ 250,000$ over a three-year period. As with the Innovation Fund, the CFI contributes 40\% of the costs and, through the Infrastructure Operating Fund, supports operations and maintenance costs. In 2003 alone, 97 awards were announced. So far, the $\mathrm{New}$ Opportunities Fund has supported the careers of well over 1,600 new faculty researchers at universities across the country.

Created in 2001, Genome Canada's (GC; www.genomecanada.ca) mandate is to provide operating funds for large-scale genomics and proteomics projects to improve Canada's position in this area. In general, funding is in the range of $C \$ 8-\$ 20$ million spread over three to four years. Using a venture-capital infrastructure model, GC consists of five regional Genome Centres-Genome Atlantic, Genome Quebec, Genome Prairie, Ontario Genomics Institute and Genome British Columbia-each of which has a Chief
Executive Officer and a Chief Scientific O fficer. Professional accountability, the prevention of conflicts of interest and highquality scientific productivity are stressed. Each of the regional Genomic Centres leverages the federal funding with partner and provincial funds. Examples of provincial government funding in 2003 include C $\$ 27.5$ million from British Columbia (www.genomebc.ca), C\$2 million from Nova Scotia (Genome Atlantic, 2003) and $C \$ 10$ million from Quebec (Genome Q uebec, 2003). So far, G enome Canada has invested more than $\mathrm{C} \$ 379$ million across Canada, which, when combined with funding from other partners, is expected to result in more than $\mathrm{C} \$ 848$ million in 78 innovative research projects. These include the Montreal Proteomics Network (www.rpmpn.mcgill.ca) and advanced, internationally competitive science and technology platforms.

$\mathrm{T}$ his unification of funding sources and the creation of a more comprehensive infrastructure to support the biomedical research community has significantly improved Canada's research profile over the past four years. The four major funding sources, the CIHR, Canada Research Chairs Program, the CFI and GC, have helped to create world-class scientific initiatives across the country that provide Canada's scientists with access to cutting-edge equipment and facilities and to the qualified and welltrained personnel needed to operate them. The CFI purchased the equipment and funded the infrastructure, GC hired and trained the qualified personnel to manage projects, operate the equipment, create central knowledge bases and analyse the data, and

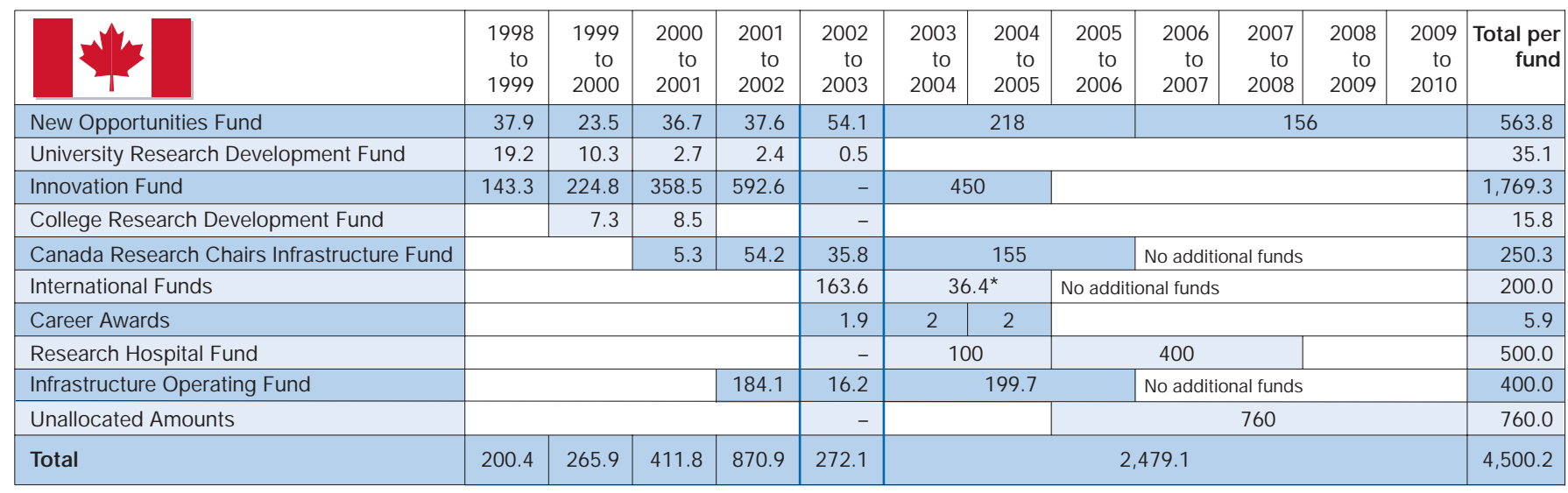

Fig2 | Committed and projected funding (C \$ million) for various Canadian Foundation for Innovation grants 1998-2010. The asterisk denotes funds that are still to beallocated. 
Table 1|Biomedical articlesassociated with Canadian scientists

\begin{tabular}{|c|c|c|c|c|c|c|c|c|}
\hline \multirow[t]{2}{*}{ Year } & \multirow[t]{2}{*}{ CIHR } & \multirow[t]{2}{*}{$\begin{array}{l}\text { Canadian research } \\
\text { chair }\end{array}$} & \multirow[t]{2}{*}{ CFI } & \multirow[t]{2}{*}{ GC } & \multicolumn{2}{|c|}{$\begin{array}{l}\text { Total biomedical articles } \\
\text { affiliated with Canada }\end{array}$} & \multicolumn{2}{|c|}{$\begin{array}{c}\text { Total biomedical articles } \\
\text { in PubMed }\end{array}$} \\
\hline & & & & & $\begin{array}{l}\text { Total papers } \\
\text { over } 1999\end{array}$ & $\%$ Increase & $\begin{array}{l}\text { Total papers } \\
\text { over } 1999\end{array}$ & $\%$ Increase \\
\hline 1999 & - & - & $\sqrt{ }$ & - & 12,721 & - & 585,671 & - \\
\hline 2000 & $\sqrt{ }$ & $\sqrt{ }$ & $\sqrt{ }$ & - & 13,653 & 6.8 & 499,434 & (14.7) \\
\hline 2001 & $\sqrt{ }$ & $\sqrt{ }$ & $\sqrt{ }$ & $\sqrt{ }$ & 14,734 & 13.7 & 599,140 & 2.2 \\
\hline 2002 & $\sqrt{ }$ & $\sqrt{ }$ & $\sqrt{ }$ & $\sqrt{ }$ & 16,033 & 20.7 & 643,903 & 9.0 \\
\hline 2003 & $\sqrt{ }$ & $\sqrt{ }$ & $\sqrt{ }$ & $\sqrt{ }$ & 16,978 & 25.1 & 612,712 & 4.4 \\
\hline
\end{tabular}

$\mathrm{CFI}$, Canada Foundation for Innovation; CIH R, Canadian Institutes of Health Research; GC, GenomeCanada.

Table 2 | Total of various commercialization indicators 1999-2001 (CFI, 2003)

\begin{tabular}{lllllll}
\hline & $\begin{array}{l}\text { Research } \\
\text { (US\$ million) }\end{array}$ & Discovery & $\begin{array}{l}\text { Licenceand } \\
\text { options }\end{array}$ & $\begin{array}{l}\text { Licenceincome } \\
\text { (US\$ million) }\end{array}$ & $\begin{array}{l}\text { US patents } \\
\text { New start-up } \\
\text { companies }\end{array}$ \\
\hline 1999 (15 institutions) & 1,052 & 671 & 201 & 12.7 & 153 & 47 \\
\hline 2000 (15 institutions) & 1,266 & 876 & 280 & 23.9 & 135 & 58 \\
\hline 2001 (19 institutions) & 1,608 & 860 & 306 & 40.6 & 152 & 65 \\
\hline
\end{tabular}

the Canada Research Chairs Program helped to attract high-profile scientists from all over the world. As a result, Canada's scientists accelerated their research and were able to remain competitive on a global level. A search of the US National Center for Biotechnology Information's PubM ed server of all biomedical journals indicates that the expansion of funding sources led to an overall increase in publications over the same period (Table 1). Similarly, it led to economic progress as well. From 1999 to 2001, Canada saw a $50 \%$ increase in support for research, a $50 \%$ increase in licences and options executed, a 200\% increase in income from licences and a $40 \%$ increase in the number of new spin-off companies created (Table 2).

While this has, without doubt, created considerable momentum, the future of Canada's success and growth of its biomedical research and biotech industry is at a crossroads. As long as policy makers remain aware of the country's future needs for short-term and long-term research funding, the momentum will be maintained. The situation looks quite positive. Since the beginning of this year, the federal government has announced further increases in funding for various granting agencies. In March 2004, Prime Minister Paul Martin stated that the government would invest a further $C \$ 585.9$ million in the CFI, C $\$ 450.7$ million into the Innovation Fund and $C \$ 135.2$ million into the Infrastructure Operating Fund (www.innovation.ca). In April, Canada's Industry M inister Lucienne Robillard announced an additional C\$138.3 million for 137 new Canada

\section{... the future of Canada's success and growth of its biomedical research and biotech industry is at a crossroads}

Research Chairs, of which 56 (41\%) were either expatriates returning or international researchers moving to Canada for the first time (www.chaires.gc.ca).

B ut next year will see some new challenges. The CFI is scheduled to wind down its funding in 2005 and has not planned new competitive projects before 2010 (Fig 2). Funding for the Infrastructure Operating Fund and the Canada Research Chairs Program will end in 2005. While GC has helped to create and staff a number of core facilities throughout Canada that house cutting-edge equipment and highly qualified, well-trained people, most of these facilities will require new money in 2005 when their GC operating grants end. A solution is needed to update and maintain equipment and personnel in order to assure the international competitiveness of these now wellestablished projects. David Strangway, President and CEO of the CFI until April 2004, discussed these concerns in a Brief to the H ouse of Commons last year (CFI, 2003), and requested that the $\mathrm{CFI}$ have the resources necessary to help institutions maintain their momentum. As a first response, the Canadian government committed an additional $C \$ 60$ million to GC in its 2004 Federal Budget. However, long-term plans need to acknowledge that most of these facilities will be at their highest level of productivity in their final year of funding (2004-2005). With most of these projects now fully deployed, as they enter their last year of operational funding, Canada is poised to accomplish even more science, at a higher standard, than was achieved in the previous three years combined. The outcome of this increase in productivity will firmly establish the country as a leader in biomedical research on an international scale and open the door for Canadian scientists to participate in major global initiatives in genomics, proteomics and other biomedical/health research.

Indeed, over the past few years, Canada has become a place of growth and excitement in biomedical research. This success is due in large part to the resurgence in funding described above. Many of the large-scale projects funded by $\mathrm{GC}$, the $\mathrm{CFI}$ and the CIHR have reached a high level of international recognition and are positioned to participate in major projects and grants on a global scale. Several have been able to obtain money from other funding agencies, including the NIH and the Wellcome Trust in the UK. At the Pan Canadian Proteomics meeting held in November 2002, with over 100 of Canada's leading scientists and leaders in the proteomics field present, the concept of rallying around a national proteomics project was embraced, as was the creation of a Canadian Proteomics N etwork. This ability of Canadians to be involved in any national initiative is contingent on Canada's continued support of the projects in which significant investment has already been made.

To ensure that Canada's investment in biomedical and health research over the past four years pays the dividends that were 


\section{science $\&$ society}

envisioned by the funding agencies, a mechanism for continuity must be planned and executed. Strangway estimated that an additional investment of $C \$ 1$ billion-or C $\$ 2.5$ billion when counting partner investments-between 2006 and 2010 is needed to maintain the existing momentum and ensure the full and effective use of research infrastructure (CFI, 2003). In the short term, the $C \$ 60$ million committed by the federal government may help to bridge funds to support some of the existing GC projects through the 2005-2006 fiscal year. These funds would allow these projects to maintain their impact while simultaneously giving the government time to create more competition in 2005 for multi-year renewal grants targeted to all the previously funded projects as well as to new applicants.

For large-scale projects, longer-term, secured financial resources for both operational (GC) and equipment (CFI) expenditures are needed for at least the next four years until 2009. Just as with previously awarded applications, these renewal grants should include a rigorous review process coupled with assurances of continued output of high-quality science from each project. Within this time frame, a clear mandate that couples scientific excellence with economic sustainability should be provided, with continued funding then contingent on achieving the well-defined milestones for each project.

The past five years have seen federal funding for biomedical research in Canada rise from $C \$ 5.1$ billion to $C \$ 7.5$ billion. The results have been a significant increase in publications, a reduction in 'brain-drain' and the establishment of numerous internationally competitive research facilities. Given the necessary continued support, the momentum is there for Canada to continue to be a leader of international innovation and high-quality research.

\section{REFERENCES}

Canada Research Chairs Program (2002) Third Year Review of the Canada Research Chairs Program. www.chaires.gc.ca

CFI (2003) Brief to the House of Commons Standing

Committee on Finance. www.innovation.ca

Cook-D eegan R (1994) The Gene Wars. Science,

Politics, and the H uman Genome. N ew York:

W W N orton \& Company

Genome Atlantic (2003) Annual Report 2003.

www.genomeatlantic.ca

Genome Q uebec (2003) Annual Report

2002-2003. www.genomequebec.com

Industry Canada (1999) International M igration of Skilled W orkers. Facts and Factors.

www.strategis.ic.gc.ca

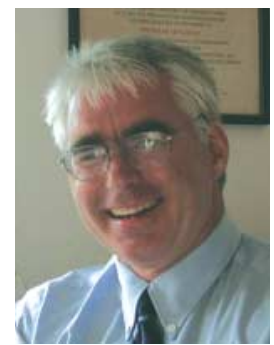

John Bergeron is D irector of the Montreal Proteomics Network (a 'Genome Q uebec'funded project) and Chair of the Department of Anatomy and Cell Biology at McGill University, Montreal, Quebec, Canada. E-mail:john.bergeron@mcgill.ca

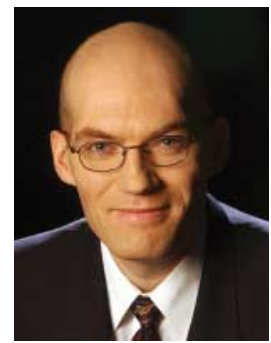

Sean Taylor is Program Manager for the Montreal Proteomics Network.

E-mail: sean.taylor@mcgill.ca

doi:10.1038/sj.embor.7400212 